\section{Oral myiasis in a patient with neurological signs}

A patient presented with oral myiasis, which is an infestation of mammalian tissue by flies of the Diptera order ${ }^{1}$ that is often related to bad oral hygiene, and is common in the tropics. He was admitted to hospital and 30 larvae were removed.

The site becomes accidentally infected when the larvae are drawn to the site to feed, and obligatory when they need a live host for development. ${ }^{2,3}$ The sites are classified as cutaneous, external openings, or internal organs. ${ }^{3}$

A 58-year-old man, presented with bad breath. He had neurological deficits since a previous stroke, he had no body control, and his mouth was always open.

On examination he had bad oral hygiene and an infection of the maxillary gingiva.

$\mathrm{He}$ was admitted and given ceftriaxone (Rocephin®, Roche) and clindamycin. Computed tomography (CT) failed to confirm the infestation.

He was operated on under general anaesthesia, his mouth cleaned, and 30 larvae (Cochliomya hominivorax) removed (Figs. 1 and 2).

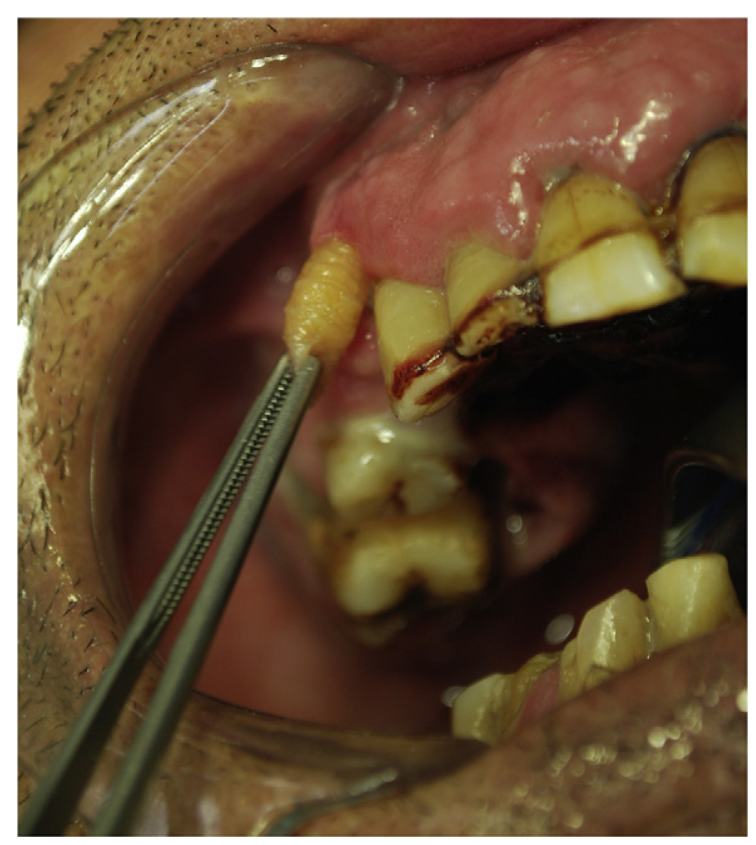

Fig. 1. The removal of a maggot from the inner gingival sulcus.

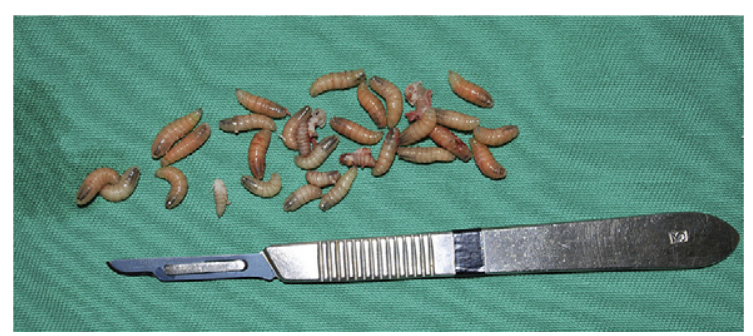

Fig. 2. The maggots removed from the patient's mouth.
His recovery was uneventful and he was discharged after four days. He was followed up weekly for three months and there were no signs of relapse. The family was instructed about oral hygiene and told to cover his mouth with a mask.

Species from the families Sarcophagidae (Wohlfahrtia magnifica $^{1}$ ), Calliphoridae (Cochliomya hominivorax $\left.{ }^{2,3}\right)$ and Dermatobia hominis ${ }^{4}$ are the main cause.

The affected patients are reported to be from poor countries, India and Brazil ${ }^{3,5}$ being the most cited. Most patients are about 44 years old and men are more affected. Poor oral hygiene, ${ }^{1,3}$ labial incompetence and periodontitis, ${ }^{5}$ are the most common abnormalities and some systemic conditions are predisposing factors, the most cited being alcohol addiction,,${ }^{1,10}$ senility, ${ }^{1}$ multiple sclerosis, ${ }^{8}$ and neurological injury. $1,2,4$

The most common signs and symptoms are oedema and pain, ${ }^{2}$ followed by mobility of the anterior maxillary teeth, the sensation of movement in the area, and gingival bleeding.

The affected sites are the mouth and face, ${ }^{2}$ including the gingival sulcus, ${ }^{1}$ anterior palate, lips ${ }^{2}$ and nose.

The standard treatment is removal, ${ }^{1-5}$ with or without turpentine oil, 5 saline irrigation, and debridement. Antibiotics are indicated, ${ }^{3-5}$ and some authors use ivermectin. ${ }^{2,3}$ We used only antibiotics.

\section{Conflict of interest}

We have no conflicts of interest.

\section{Ethics statement/confirmation of patient's permission}

The patient's family gave informed consent.

\section{References}

1. Özdemir EC, Eksi F, Şenyurt SZ, et al. A case of gingival myiasis caused by Wohlfahrtia magnifica. Mikrobiyol Bul 2014;48:512-7.

2. Antunes AA, Santos Tde S, Avelar RL, et al. Oral and maxillofacial myiasis: a case series and literature review. Oral Surg Oral Med Oral Pathol Oral Radiol Endod 2011;112:e81-5.

3. Daltoé FP, Nosé AR, Nosé FR, et al. Oral myiasis in two children. Pediatr Infect Dis J 2013;32:572-3.

4. Freitas DA, Moreira G, Jones KM, et al. Social exclusion and myiasis of the upper lip in a Brazilian rural resident. Rural Remote Health 2012;12:2188.

5. Srivastava R, Devi P, Thimmarasa VB, et al. Flies blown disease - oral myiasis. Indian J Dent Res 2011;22:615.

Carlos Alberto Ribeiro Neto ${ }^{a}$ Marcelo Silva Monnazzi ${ }^{\mathrm{b}, *}$

${ }^{a}$ Faculty of Dentistry of Araraquara, UNESP, Brazil

${ }^{\mathrm{b}}$ Oral and Maxillofacial Surgeon, Volunteer Professor at the Faculty of Dentistry of Araraquara, Diagnoses and Oral and Maxillofacial Surgery Department, UNESP, Brazil 
* Corresponding author at: Rua Voluntarios da Patria, 2777, ap 1001, Araraquara, São Paulo, Brazil. Tel.: +551697823532; +5516 33845822 .

E-mail address: monnazzi@ig.com.br (M.S. Monnazzi)

Available online 30 April 2016

http://dx.doi.org/10.1016/j.bjoms.2016.04.018

\section{Apparently aberrant fixation of a fracture of the oblique angle of the mandible}

A 56-year-old man presented with a fracture of the angle of his left mandible after a fall. Through a transbuccal approach, we did an open reduction and achieved internal fixation of the fracture with a single $2 \mathrm{~mm}$ miniplate on the lateral surface of the mandible. We extracted the lower left third molar to help us with the reduction.

The postoperative plain radiographs showed that the fixation plate was distal to the position of the fracture although he had a good postoperative occlusion (Fig. 1). Threedimensional computed tomography (CT) showed a fracture of the buccal cortex of the angle of the mandible, which we had correctly plated (Fig. 2). We did not see this fracture line on the standard plain radiographs as it was undisplaced and part of the pattern of the sagittal fracture. The unfixed fracture that was seen on the orthopantogram was that of the lingual cortex, which was more proximally placed.

Although we take plain radiographs routinely to aid diagnosis and confirm adequate postoperative reduction and
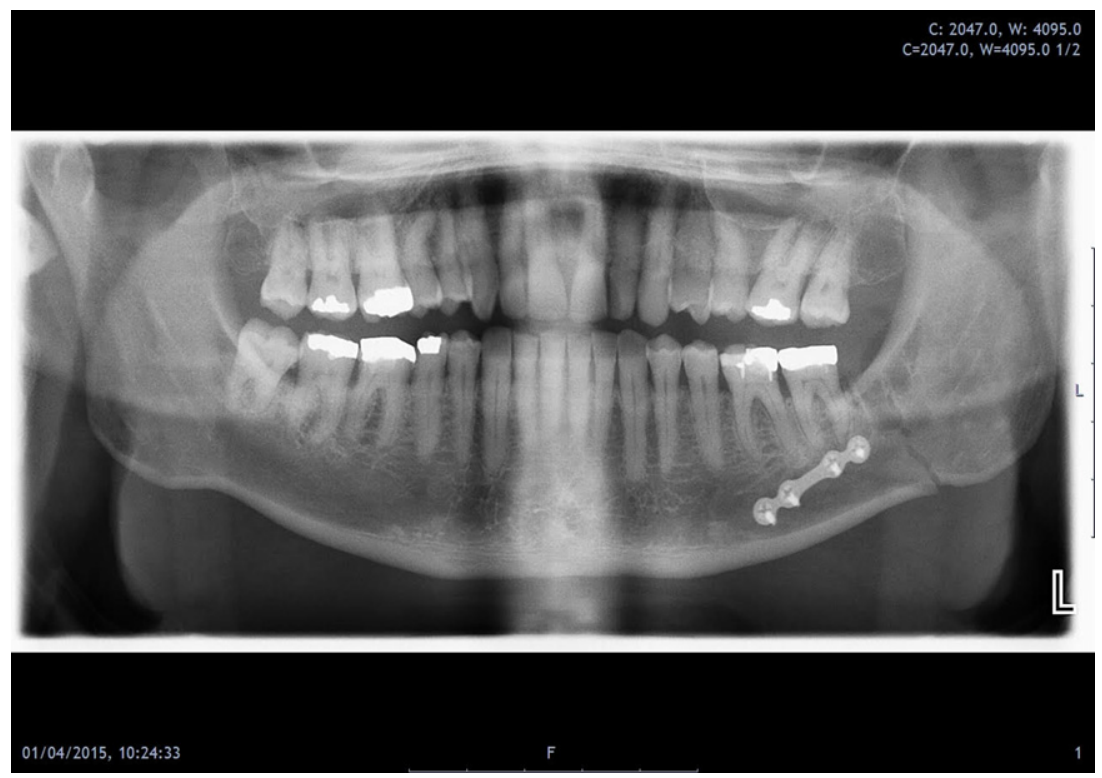

Fig. 1. Postoperative radiograph showing the apparently aberrant fixation of the fracture.

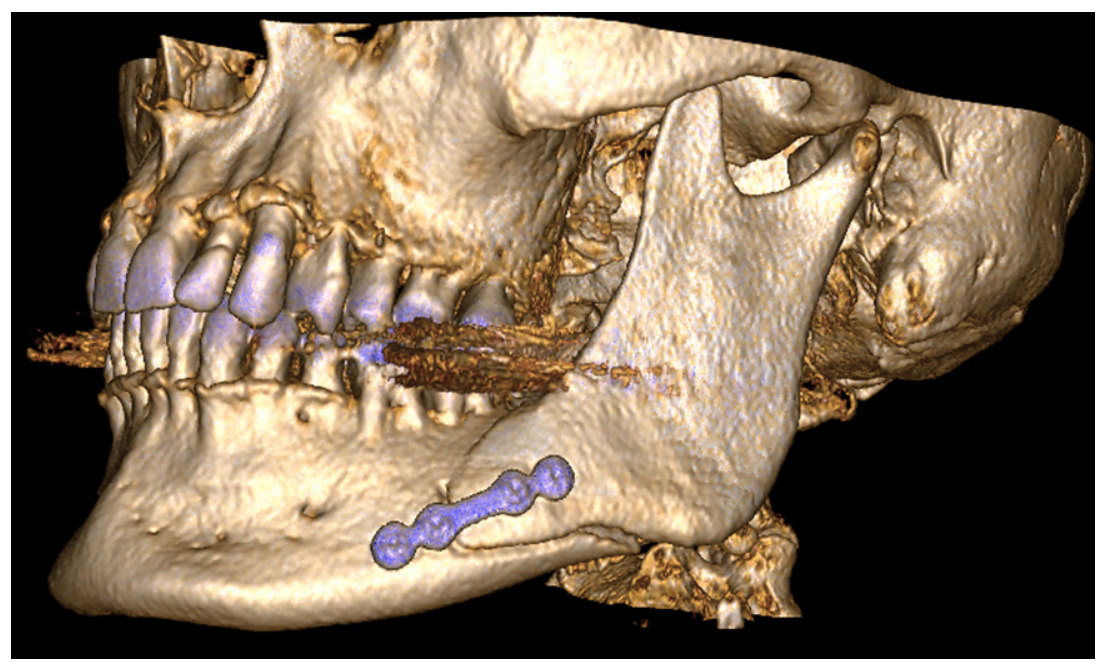

Fig. 2. Computed tomogram of the mandible that confirms the position of the miniplate overlying the fracture of the angle of the left mandible. 